\title{
Menstrual hygiene practices among adolescent girls in rural area of India
}

\author{
M. Ajay Kausheic, Karthikeyan K., Shagirunisha Rizvana A. M.*, B. Ganesh Babu
}

Department of Community Medicine, Dhanalakshmi Srinivasan Medical College, Perambalur, Tamil Nadu, India

Received: 30 March 2021

Accepted: 30 April 2021

\section{*Correspondence:}

Dr. Shagirunisha Rizvana A. M.,

E-mail: shagirunisha.1993@gmail.com

Copyright: () the author(s), publisher and licensee Medip Academy. This is an open-access article distributed under the terms of the Creative Commons Attribution Non-Commercial License, which permits unrestricted non-commercial use, distribution, and reproduction in any medium, provided the original work is properly cited.

\begin{abstract}
Menstruation and menstrual practices still face many social, cultural, and non secular restrictions which is an enormous barrier within the path of menstrual hygiene management. In many parts of the country especially in rural areas girls aren't prepared and aware of menstruation in order that they face many difficulties and challenges reception, schools, and work places. In rural areas, women don't have access to sanitary products or they know little about the kinds and method of using them or are unable to afford such products due to high cost. So, they mostly believe reusable cloth pads which they wash and use again. Implementation of recent techniques like incineration can help to scale back the waste. Also, awareness should be created to stress the utilization of reusable sanitary products or the natural sanitary products made up of materials like banana fibre, bamboo fibre, sea sponges, water hyacinth, and so on.
\end{abstract}

Keywords: Menstruation, Hygiene, Disposal, Taboos

\section{INTRODUCTION}

According to World Health Organization (WHO), an individual aged 10-19 years is taken into account as a teenager. The transition period between the kid hood and adulthood is named adolescence which is marked with the expansion and development of the child. It is recognized as a special period during a girl's life cycle which needs special attention. Menarche is a crucial biological milestone during a woman's life because it marks the onset of the reproductive phase of her life. The average age at menarche is usually consistent across the populations that are, between 12 and 13 years aged. ${ }^{1}$

\section{MENSTRUAL CYCLE}

This cycle has three phases, that is, follicular phase (proliferative), ovulation phase, and secretory phase (secretory). Menstruation is regulated by hormones; during this process, endometrium, lining of uterus, gradually thickens and sheds off and causes bleeding that normally last for 3-5 days and infrequently up to 7 days. Menstruation sheds two-thirds of the endometrial lining. In addition to blood, menstrual fluid contains mucus and vaginal secretions. Menstrual fluid may or might not have unpleasant odor especially when it comes in touch with air. Menstrual flow or duration also changes before menopause or during gynecological cancers. Under conditions of hormonal imbalance, fibroids, polyps, and endometriosis menorrhea increase and excessive loss of blood through menstruation can cause anemia.

Practices associated with menstruation hygiene are of major concern because it features a health impact; if neglected, it results in toxic shock syndrome, reproductive tract infections (RTI), and other vaginal diseases. $^{2}$

Poor genital hygiene negatively affects adolescents' health. Most girls are unaware and unprepared for menarche as they're not informed or ill-informed about menstruation. 
The main objective includes both a summary of the prevailing menstrual hygiene needs and management and also an analysis of the present knowledge on menstruation hygiene management.

\section{CULTURAL BELIEF AND RESTRICTIONS DURING MENSTRUATION}

Menstrual hygiene practices were affected by cultural norms, parental influence, personal preferences, economic status, and socioeconomic pressures. Menstrual beliefs ask misconceptions and attitudes towards menstruation within a given culture or religion. Menstrual beliefs, knowledge, and practices were all interrelated to the menstrual hygiene management. ${ }^{3}$

These norms were the barriers within the path of excellent menstrual hygiene practices. Many ladies experiencing restrictions on cooking, work activities, sexual activity, bathing, worshipping, and eating certain foods.

These restrictions were thanks to the general perception of the people regarding menstruation as they consider it dirty and polluting. ${ }^{4}$

In some parts of the country there have been restrictions on bathing and a taboo against burial of bloodied menstrual cloth. Cloths should first be washed then buried or reused. Washing and drying thought to be done secretly or during a hidden corner in order that it can't be seen by others.

It had been also believed that menstrual fluids could also be misused for sorcery, so women should wash the wrapper/cloth wore during menses only in the dark when others were asleep. ${ }^{5}$

Menorrhea was seen as dirty, polluting, and shameful, so women hide menstrual cloths for fear of being cursed. In similar findings, it had been believed that menstrual waste was linked to witchcraft and danger, so it must be buried unless witches follow human blood and find the menstrual wrapper/cloth and destroy the ladies by causing infertility.

From of these beliefs, it had been clear that education plays a key role in menstruation hygiene management. By educating both men and ladies regarding menstruation, we will overcome these false beliefs and taboos. Thanks to cultural expectations and restrictions many ladies weren't adequately informed about the realities of menstruation. As a result, they feel subnormal, diseased, or traumatized.

Unprepared girls were frightened, confused, and feel embarrassed by menarche likely to develop negative attitudes towards menstruation. ${ }^{6}$

Even touching of menstruating women was considered toxic; they were prohibited from cooking and from taking certain foods like pickle. These prohibitions are more within the rural areas than within the urban areas. They were also not allowed to participate in religious activities or to contact religious articles. ${ }^{7}$

Menstruating girls also are not allowed to bath and wash hair, because it is believed to impede blood flow.

\section{TYPES OF ABSORBENTS USED DURING MENSTRUATION}

Reusable and washable cloth pads, commercial sanitary pads, tampons, reusable tampons, menstrual cups and bamboo and banana fibre pads.

\section{MENSTRUAL WASTE DISPOSAL TECHNIQUES USED BY WOMEN}

In schools, thanks to lack of sanitary facilities, girls throw their pads in toilets. In some cases, girls threw away their used menstrual clothes without washing them. Also many were reported being absent from school thanks to lack of disposal system, broken lock/doors of toilets, lack of water faucet, bucket, and poor water system. ${ }^{6}$

In some schools, incinerators or "feminine hygiene bins" are used for disposing menstrual waste but thanks to shyness or fear of being seen by others they avoided using it. ${ }^{8}$

\section{Behavior of women at home and outside home}

The behavior of girls regarding disposal is different when being reception and faraway from home. At home, they dispose the waste by wrapping and throwing within the dustbin along side other domestic waste. As mentioned above, the disposing habits change consistent with the place. In public places, before having knowledge about the results of flushing the pads, they flush them within the toilets or wrap and throw them within the dustbins. Where dustbins aren't placed they leave the soiled pads wrapped or unwrapped within the rest room corners. This makes the toilets dirty, breeding place for flies and mosquitoes, and also unhygienic for other toilet users and cleaners

\section{ROLE OF MEN/BOYS TOWARDS MENSTRUAL HYGIENE MANAGEMENT}

Men can support and influence women and girls in managing menstruation in households, schools, work, and community through many roles as husbands, fathers, brothers, students, teachers, colleagues, leaders, and policymakers. It had been found that at household level men don't support women regarding menstruation hygiene and never have they discussed menstrual issues with their wives and daughters. As they're decisionmakers at household level, in many cases they are doing not give money to shop for menstrual products like commercial sanitary pads, tampons, and menstrual cups 
as they consider it money wastage. So women need to believe cheap reusable cloth pads which they need to scrub, dry, and use again. In other cases, thanks to low family income, men hesitate to offer money for such costly products. So, in both cases, women have to compromise with their menstrual needs and personal hygiene. $^{4}$

\section{ROLE OF TEACHERS IN CREATING AWARENESS REGARDING MENSTRUATION AND MENSTRUAL WASTE MANAGEMENT}

\section{Reason for absenteesim in schoo}

Menstruation may be a silent issue in girl's life which is further suffering from teacher's attitude, school environment, and infrastructure. Because of this,many girls remain absent from schools during this point. Sex education is usually neglected from the varsity curriculum which negatively impacts the student's life. They get information about puberty, sexual activity menstruation, and other physiological changes in one's body from books, friends, and Internet which can be incomplete or inaccurate. Due to lack of data and social interaction, teasing and taunting with hurtful nicknames are common in schools. This makes it difficult for a woman student to survive during this environment, in order that they remain absent from school.

In many faculties, both male and feminine teachers aren't able to discuss menstruation and menstrual hygiene management with students. The female teachers also are not available in many faculties. Teachers often skip such topics in books as they are doing not want any open discussion within the class or to flee from the questions asked by students. Teachers also feel shy and embarrassed to discuss such topics in class due to language barrier. ${ }^{4}$

\section{Language barrier}

In most faculties, English isn't a compulsory subject so teachers need to discuss them in local language and using vernacular words ahead of scholars is an embarrassing thing. Due to unsupportive environment within the schools, it had been also found that some girls hesitate to face to answer teacher's questions in fear of leakage or smell and also hesitate to write down on blackboard in fear of any menstrual accident and blood stains on clothes seeing by others. In some reported cases, parents don't allow girls to travel to colleges upon reaching puberty in fear of harassment by boys and male teachers in schools. ${ }^{9}$

\section{Organizational work to improve hygiene practice}

To overcome these issues, male teachers and employees within the schools and institutes should be educated and assured regarding menstruation and menstrual hygiene management in order that they support girls/women by providing safe environment and privacy. A committee of teachers including both male and females should be made within the schools to gather funds for providing sanitary napkins, soaps, water, and toilet facilities in schools so that girls manage their menstruation with ease and safety. Committee should also provide dustbins for menstrual waste disposal. Separate toilets for women and boys with proper doors and locks should be inbuilt the faculties. Teachers should educate girls about menstrual health management and its link to their health. They should also make girl students conscious of the way to eliminate used menstrual products reception and in schools and about the results of throwing them in open or flushing them in toilets. Open discussions on puberty, sex education, menstruation, then forth should be organized by schools in every class to form students aware. This will solve their unsolved queries by providing them correct knowledge, promote social interaction, and also develop a trust relationship with fellow friends and teachers. School-level health policies should be made by school management committee to market and educate students regarding health and safety, to make sure adequate water and sanitation facilities, and to guard girl students and staff from bullying and sexual harassment

\section{STEPS TO MANAGE MENSTRUAL WASTES:}

Disposal of menstrual waste is of major concern because it affects health and environment. There is a requirement for effective menstrual materials which needs less and cost-effective management.

Companies handling manufacturing of sanitary pads or other articles should disclose the knowledge on the pads regarding the chemical composition of the pads in order that appropriate technologies could be used for their disposal and treatment

Environment-friendly chemicals should be employed by manufacturers of sanitary products to prevent soil and pollution and to lock the decomposition process.

Guidance regarding menstrual management to adolescent girls and ladies may be a much needed step. Menstrual hygiene management should be an integral a neighborhood of education curriculum.

\section{BETTER WAYS FOR DISPOSING MENSTRUAL WASTES}

Incinerators, latrines with chutes, reusable cloth pads, biodegradable products and clay or cemented incinerators.

Better disposal techniques- pads should be properly wrapped in newspaper then thrown in dustbin.

\section{CONCLUSION}

Menstrual hygiene should be promoted by implementing a course on menstruation and menstrual hygiene 
management. Teachers should be educated and trained to impart knowledge about menstruation and menstrual hygiene management among students. Social and electronic media also play an important role to make the ladies and ladies conscious of the most recent menstrual products, different manufacturers, government policies, then forth. Subsidies should tend on menstrual products so as that each girl/women can afford them easily. Nongovernment organizations should come to the fore to show rural people about menstruation, menstrual hygiene management, importance of toilets at homes, hand washing, diseases related to reproductive tract because of poor hygiene, then forth. Emphases should tend on the use of reusable sanitary or cloth pads to beat the matter of disposal. Girls and ladies should remember of the results of disposing used menstrual products in open or flushing them in toilets. Dustbins with proper lids should be placed within the toilets. If possible, incinerators should be installed at homes, schools, and community levels. This study reveals that lack of privacy could also be a serious concern both in household and in schools. Also, ignorance, misconceptions, unsafe practices, and illiteracy of the mother and child regarding menstruation are the idea causes of the various problems. So, there's a huge need to encourage adolescents at school levels to practice safe and hygienic behaviors.

Funding: No funding sources

Conflict of interest: None declared

Ethical approval: Not required

\section{REFERENCES}

1. WHO Health problems of adolescents. Technical report series 308. World Health Organization, Geneva. $1965 . \quad$ https://apps.who.int/iris/ handle/10665/38425. Accessed on 01 February 2021.

2. Khanna A, Goyal RS, Bhawsar R. Menstrual Practices and Reproductive Problems: A Study of Adolescent Girls in Rajasthan. 2005; 1 .

3. Menarche SSDEAT, Amann-Gainotti, Merete. Adolescence. Roslyn Heights, N.Y. 1986;21(83):703.

4. School menstrual hygiene management in Malawi: More than toilets. IRC. 2011:21-3.

5. Sommer M, Kjellén M, Pensulo C. Girls' and women's unmet needs for menstrual hygiene management (MHM): The interactions between MHM and sanitation systems in low-income countries. J Water Sanit Hyg Dev. 2013;3(3):28397.

6. Dhingra R, Kumar A, Kour M. Knowledge and Practices Related to Menstruation among Tribal (Gujjar) Adolescent Girls. 2009;3(1):43-8.

7. Bott S. Towards adulthood: exploring the sexual and reproductive health of adolescents in South Asia. WHO. 2003. http://apps.who.int/iris/bitstream/ handle/10665/42781/9241562501.pdf?sequence $=1$. Accessed on 1 February 2021.

8. Jasper C, Le T, Bartram J. Water and Sanitation in Schools: A Systematic Review of the Health and Educational Outcomes. 2012;2772-87.

9. Health AR. Menstruation in Rural Igbo Women of South East Nigeria: Attitudes, Beliefs and Practices. 2008;109-15.

Cite this article as: Kausheic MA, Karthikeyan K, Rizvana SAM, Babu BG. Menstrual hygiene practices among adolescent girls in rural area of India. Int J Community Med Public Health 2021;8:3180-3. 